\title{
Age-dependent molecular alterations in the autophagy pathway in HIVE patients and in a gp120 tg mouse model: reversal with beclin-1 gene transfer
}

\author{
Jerel Fields • Wilmar Dumaop • Edward Rockenstein • \\ Michael Mante • Brian Spencer • Igor Grant • Ron Ellis • \\ Scott Letendre • Christina Patrick • Anthony Adame • \\ Eliezer Masliah
}

Received: 12 October 2012 /Revised: 26 November 2012 / Accepted: 29 November 2012 / Published online: 24 January 2013

(C) The Author(s) 2013. This article is published with open access at Springerlink.com

\begin{abstract}
Aged ( $>50$ years old) human immunodeficiency virus (HIV) patients are the fastest-growing segment of the HIV-infected population in the USA and despite antiretroviral therapy, HIV-associated neurocognitive disorder (HAND) prevalence has increased or remained the same among this group. Autophagy is an intracellular clearance pathway for aggregated proteins and aged organelles; dysregulation of autophagy is implicated in the pathogenesis of Parkinson's disease, Alzheimer's disease, and HAND. Here, we hypothesized that dysregulated autophagy may contribute to aging-
\end{abstract}

\footnotetext{
J. Fields $\cdot$ W. Dumaop $\cdot$ E. Masliah

Department of Pathology, University of California

San Diego, La Jolla, CA 92093, USA

E. Rockenstein $\cdot$ M. Mante $\cdot$ B. Spencer $\cdot$ R. Ellis $\cdot$ C. Patrick

A. Adame $\cdot$ E. Masliah $(\bowtie)$

Departments of Pathology and Neurosciences,

School of Medicine, University of California San Diego,

9500 Gilman Dr., MTF 348,

La Jolla, CA 92093-0624, USA

e-mail: emasliah@ucsd.edu

S. Letendre

Departments of Pathology, School of Medicine,

University of California San Diego,

La Jolla, CA 92093, USA

I. Grant

Departments of Pathology and Psychiatry,

University of California San Diego,

La Jolla, CA 92093, USA

Present Address:

B. Spencer

NeuroTransit Inc, University of California San Diego,

San Diego, CA 92121, USA
}

related neuropathology in HIV-infected individuals. To explore this possibility, we surveyed autophagy marker levels in postmortem brain samples from a cohort of wellcharacterized $<50$ years old (young) and $>50$ years old (aged) HIV+ and HIV encephalitis (HIVE) patients. Detailed clinical and neuropathological data showed the young and aged HIVE patients had higher viral load, increased neuroinflammation and elevated neurodegeneration; however, aged HIVE postmortem brain tissues showed the most severe neurodegenerative pathology. Interestingly, young HIVE patients displayed an increase in beclin-1, cathepsin-D and light chain (LC)3, but these autophagy markers were reduced in aged HIVE cases compared to age-matched HIV+ donors. Similar alterations in autophagy markers were observed in aged gp120 transgenic (tg) mice; beclin-1 and LC3 were decreased in aged gp120 tg mice while mTor levels were increased. Lentivirusmediated beclin-1 gene transfer, that is known to activate autophagy pathways, increased beclin-1, LC3, and microtubule-associated protein 2 expression while reducing glial fibrillary acidic protein and Ibal expression in aged gp120 tg mice. These data indicate differential alterations in the autophagy pathway in young versus aged HIVE patients and that autophagy reactivation may ameliorate the neurodegenerative phenotype in these patients.

Keywords Aging $\cdot \mathrm{HIV} \cdot$ Autophagy $\cdot \mathrm{gp} 120 \cdot$ Beclin-1

\section{Introduction}

Currently, over 30 million people live with human immunodeficiency virus (HIV) worldwide. In the USA, the aging population represents one of the fastest-growing groups 
with HIV (Scott et al. 2011). The Center for Disease Control (CDC) estimates that by the year 2015, half of all Americans living with HIV will be over the age of 50 (Smith 2005). In the central nervous system (CNS), microglial cells have been identified as a primary reservoir for HIV infection (Gendelman et al. 1997; Gonzalez-Scarano and MartinGarcia 2005; Haas et al. 2000; Wiley et al. 1996) with productive infection also detected in astrocytes (CarrollAnzinger and Al-Harthi 2006). Modern treatments with highly active antiretroviral therapy regimens result in HIV suppression and immune recovery, however the prevalence of HIV-associated neurocognitive disorders (HAND) and neurodegeneration (Budka et al. 1987; Cherner et al. 2007; Gendelman et al. 1997; Heaton et al. 2010, 2011; Wiley and Achim 1994) has remained the same or increased (Joska et al. 2010) in particular among people over the age of 50.

The mechanisms of neurodegeneration in aged individuals with HAND are not completely understood; however, HIV activates apoptotic pathways (Kaul et al. 2001), dysregulates calcium homeostasis (Lipton 1994; Nath et al. 2000, 2002) and promotes oxidative stress (Norman et al. 2008). Moreover, recent studies have shown that HIV proteins might interfere with clearance pathways such as autophagy (Alirezaei et al. 2008a, b; Zhou et al. 2011), a pathway necessary for protein quality control and elimination of defective older intracellular organelles (Cuervo 2004). Autophagy is a complex process that involves nucleation, initiation, elongation, and termination proteins. Initially, a phagophore forms and develops into the autophagosome, a double-membrane sac that delivers cytoplasmic material to the lysosomal compartment for degradation (Codogno et al. 2012). During the aging process, deficits in autophagy have been described in Alzheimer's disease (AD; Nixon et al. 2005; Pickford et al. 2008), Parkinson's disease (PD; Crews et al. 2010; Cuervo et al. 2004), and other aging-related disorders (Cuervo 2004). Specifically, the autophagy nucleation protein beclin- 1 and closure protein light chain (LC)3 have been implicated in human disease (Crews et al. 2010; Gozuacik and Kimchi 2004; Jaeger and Wyss-Coray 2010). Similarly, neurodegeneration has been linked to defects in autophagy in patients with HIV (Alirezaei et al. 2008a, b; Zhou et al. 2011).

We have recently shown that in the CNS of young HIV human cases and in young transgenic ( $\mathrm{tg}$ ) mice expressing HIV-gp120 protein (gp120 tg; Toggas et al. 1994), abnormal functioning of the autophagy pathway (Zhou et al. 2011) is associated with progressive accumulation of amyloid-beta (A $\beta$; Achim et al. 2009), $\alpha$-synuclein ( $\alpha$-syn; EbrahimiFakhari et al. 2011; Everall et al. 2009; Khanlou et al. 2009), and tau (Patrick et al. 2011). In contrast, activation of autophagy by gene therapy recovers the deficits in autophagy observed in $\alpha$-syn tg mice (Spencer et al. 2009). However, the mechanisms by which HIV proteins might interfere with autophagy during aging are unknown. Here, we postulate that dysfunctional autophagy activity may contribute to HAND progression in aged individuals. In this report, we extend our past studies by characterizing differences in viral load (VL), CNS immune activation and expression of autophagy-related proteins among $<50$ years old (young) and $>50$ years old (aged) HIV-infected individuals. Our results indicate that while autophagy was upregulated in the brains of young HIVE patients, it was downregulated in the brains of aged HIVE patients. Similarly, autophagy was downregulated in aged gp120 tg mice and activation with beclin-1 gene transfer ameliorated the neurodegenerative phenotype. These findings provide novel insight and potentially important targets to combat HAND in the aging population.

\section{Methods}

\section{Study population}

For the present study, we included a total of $83 \mathrm{HIV}+$ cases, of which 50 are below 50 years and 33 are above 50 years (Table 1) from the HIV Neurobehavioral Research Center and California Neuro-Acquired Immunodeficiency Syndrome (AIDS) Tissue Network at the University of California, San Diego. Cases had neuromedical and neuropsychological examinations within a median of 12 months before death. Most cases died as a result of acute bronchopneumonia or septicemia and autopsy was performed within $24 \mathrm{~h}$ of death. Autopsy findings were consistent with AIDS and the associated pathology was most frequently due to systemic cytomegalovirus (CMV), Kaposi sarcoma, and liver disease. Subjects were excluded if they had a history of CNS opportunistic infections or non-HIV-related developmental, neurologic, psychiatric, or metabolic conditions that might affect CNS functioning (e.g., loss of consciousness exceeding $30 \mathrm{~min}$, psychosis, substance dependence). The diagnosis of HIV encephalitis was based on the presence of microglial nodules, astrogliosis, HIV p24-positive cells, and myelin pallor.

Determination of HIV p24 levels in postmortem samples

HIV-1 p24 levels in postmortem tissues were determined using a commercially available p24 enzyme-linked immunosorbent assay (ELISA; NEK050001KT, PerkinElmer, Waltham, MA, USA). In brief, as previously described (Hashimoto et al. 2002), tissues from human brain samples $(0.1 \mathrm{~g})$ were homogenized in $0.7 \mathrm{~mL}$ of fractionation buffer containing phosphatase and protease inhibitor cocktails (Calbiochem, San Diego, CA, USA). Samples were precleared by centrifugation at $5,000 \times \mathrm{g}$ for $5 \mathrm{~min}$ at room 
Table 1 Summary of subject demographic and brain pathology information

\begin{tabular}{lllllll}
\hline Group & $n$ & Gender F/M & Age & PMI (h) & Brain weight (g) & Brain pathology \\
\hline Under 50 (young) & 50 & $5 / 45$ & $39.2 \pm 6.04$ & $14.0 \pm 12.13$ & $1317 \pm 131.3$ & $\begin{array}{c}\text { 20 Normal, 1 Alzheimer type II gliosis, 6 microglial } \\
\text { nodule encephalitis, 17 HIV encephalitis, 6 other }\end{array}$ \\
50 and older (aged) & 33 & $5 / 28$ & $55.2 \pm 5.51$ & $23.6 \pm 24.49$ & $1336 \pm 176.5$ & $\begin{array}{c}\text { 13 Normal, 6 Alzheimer type II gliosis, 1 microglial } \\
\text { nodule encephalitis, 8 HIV encephalitis, 5 other }\end{array}$ \\
\hline
\end{tabular}

temperature. Homogenate was analyzed for protein quantity by BCA assay (Thermo Scientific) and then $100 \mu \mathrm{g}$ of protein from each sample was assayed for p24 using the manufacturer's protocol.

\section{Generation of gp120 tg mice}

For studies of autophagy function, an animal model of HIV protein-mediated neurotoxicity, aged (12 months) tg mice expressing high levels of gp120 under the control of the glial fibrillary acidic protein (GFAP) promoter were used (Toggas et al. 1994). These mice develop neurodegeneration accompanied by astrogliosis, microgliosis, and memory deficits in the water maze test (Toggas et al. 1994). The mice were sacrificed within 1 week of behavioral testing and brains were removed for biochemical analyses of frozen or fixed brain tissues.

\section{Construction of lentivirus vectors}

The mouse beclin-1 cDNA (Open Biosystems) was PCR amplified and cloned into the third-generation selfinactivating lentivirus vector (Naldini et al. 1996a, b) with the CMV promoter driving expression producing the vector LV-beclin-1. Lentiviruses expressing beclin-1, luciferase or empty vector (as controls) was prepared by transient transfection in 293 T cells (Naldini et al. 1996a, b; Tiscornia et al. 2006; Spencer et al. 2009).

Mouse lines and intracerebral injections of lentiviral vectors

A cohort of aged (12 months) mice $(n=20), \operatorname{gp} 120 \operatorname{tg}(n=$ $10)$, and control mice $(n=10)$ were injected with $3 \mu$ of the lentiviral preparations $\left(2.5 \times 10^{7} \mathrm{TU}\right)$ into the temporal cortex (using a $5 \mu \mathrm{l}$ Hamilton syringe). Briefly, as previously described (Marr et al. 2003), mice were placed under anesthesia on a Koft stereotaxic apparatus and coordinates (hippocampus: AP, $2.0 \mathrm{~mm}$; lateral, $1.5 \mathrm{~mm}$; depth, $1.3 \mathrm{~mm}$ and cortex: AP, $0.5 \mathrm{~mm}$; lateral, $1.5 \mathrm{~mm}$; depth, $1.0 \mathrm{~mm}$ ) were determined as per the Franklin and Paxinos (1997) atlas. The lentiviral vectors were delivered using a Hamilton syringe connected to a hydraulic system to inject the solution at a rate of $1 \mu \mathrm{l}$ every $2 \mathrm{~min}$. To allow diffusion of the solution into the brain tissue, the needle was left for an additional $5 \mathrm{~min}$ after the completion of the injection. Mice received unilateral injections (right side) to allow comparisons against the contralateral side, with either LVbeclin-1 $(n=5)$ or LV-control $(n=5)$. Additional controls were performed by injecting non-tg littermates with either LV-beclin-1 $(n=5)$ or LV-control $(n=5)$. Mice survived for 3 months after the lentiviral injection. As an additional control for LV injection, age-matched littermates were injected with LV-luciferase.

Since no differences were observed between the LVcontrol and the LV-luciferase, all data presented in this paper are shown with the LV-control vector. Following National Institutes of Health (NIH) guidelines for the humane treatment of animals, mice were anesthetized with chloral hydrate and flush-perfused transcardially with $0.9 \%$ saline. Brains and peripheral tissues were removed and divided in sagittal sections. The right hemibrain was post-fixed in phosphate-buffered $4 \%$ PFA (pH7.4) at $4{ }^{\circ} \mathrm{C}$ for $48 \mathrm{~h}$ for neuropathological analysis, while the left hemibrain was snap-frozen and stored at $-70{ }^{\circ} \mathrm{C}$ for subsequent RNA and protein analysis.

\section{Antibodies}

For western blot and immunohistochemical analysis of the autophagy pathway, polyclonal antibodies against GFAP (MAB3402, dilution 1:500, Millipore), cathepsin-D (1:500, Calbiochem, San Diego, CA, USA), Iba-1 (1:1,000, Wako Corp., Japan), microtubule-associated protein (MAP) 2 (MAP378, 1:250, Millipore), LC3 (1:1,000, Abcam), mTor (1:1,000, Sigma), beclin-1 (1:1,000, Novus Biologicals, Littleton, CO, USA).

Immunoblot analysis

Frontal cortex tissues from human and mouse brains were homogenized and fractionated using a buffer that facilitates separation of the membrane and cytosolic fractions $(1.0 \mathrm{mmol} / \mathrm{L}$ HEPES, $5.0 \mathrm{mmol} / \mathrm{L}$ benzamidine, $2.0 \mathrm{mmol} /$ L 2-mercaptoethanol, $3.0 \mathrm{mmol} / \mathrm{L}$ EDTA, $0.5 \mathrm{mmol} / \mathrm{L}$ magnesium sulfate, $0.05 \%$ sodium azide; final $\mathrm{pH}, 8.8$ ). In brief, as previously described (Hashimoto et al. 2002), tissues from human and mouse brain samples $(0.1 \mathrm{~g})$ were homogenized in $0.7 \mathrm{~mL}$ of fractionation buffer containing 
phosphatase and protease inhibitor cocktails (Calbiochem, San Diego, CA, USA). Samples were precleared by centrifugation at $5,000 \times g$ for $5 \mathrm{~min}$ at room temperature. Supernatants were retained and placed into appropriate ultracentrifuge tubes and were centrifuged at $436,000 \times \mathrm{g}$ for $1 \mathrm{~h}$ at $4{ }^{\circ} \mathrm{C}$ in a TL-100 rotor (Beckman Coulter, Brea, CA, USA). This supernatant was collected as representing the cytosolic fraction, and the pellets were resuspended in $0.2 \mathrm{~mL}$ of buffer and rehomogenized for the membrane fraction.

After determination of the protein content of all samples by BCA protein assay (Thermo Fisher Scientific, Rockford, IL, USA), homogenates were loaded (20 $\mu \mathrm{g}$ total protein/ lane), separated on 4-12\% Bis-Tris gels and electrophoresed in $5 \%$ HEPES running buffer, and blotted onto Immobilon-P $0.45 \mu \mathrm{m}$ membrane using NuPage transfer buffer. The membranes were blocked in either $5 \%$ nonfat milk $/ 1 \%$ BSA in phosphate-buffered saline (PBS) $+0.05 \%$ Tween-20 (PBST) or in $5 \%$ BSA in PBST for $1 \mathrm{~h}$. Membranes were incubated overnight at $4{ }^{\circ} \mathrm{C}$ with primary antibodies. Following visualization, blots were stripped and probed with a mouse monoclonal antibody against Actin (1:2,000, mab1501, Millipore, Billerica, MA, USA) as a loading control. All blots were then washed in PBS, $0.05 \%$ tween-20 and then incubated with secondary species-specific antibodies (American Qualex, 1:5,000 in BSA-PBST) and visualized with enhanced chemiluminescence reagent (Perkin-Elmer). Images were obtained and semiquantitative analysis was performed with the VersaDoc gel imaging system and Quantity One software (Bio-Rad).

immunohistochemistry, image analysis, and laser scanning confocal microscopy

Briefly, as previously described (Masliah et al. 2003), freefloating $40 \mu \mathrm{m}$ thick vibratome sections were washed with Tris-buffered saline (TBS, $\mathrm{pH} 7.4$ ), pretreated in $3 \% \mathrm{H}_{2} \mathrm{O}_{2}$, and blocked with $10 \%$ serum (Vector Laboratories, Burlingame, CA, USA), $3 \%$ bovine serum albumin (Sigma), and $0.2 \%$ gelatin in TBS-Tween. For human brains, sections from the midfronal cortex were used; for the mice, sagittal sections from the complete brain were studied. Sections were incubated at $4{ }^{\circ} \mathrm{C}$ overnight with the primary antibodies. Sections were then incubated in secondary antibody (1:75, Vector), followed by Avidin Dhorseradish peroxidase (HRP, ABC Elite, Vector) and reacted with diaminobenzidine $(0.2 \mathrm{mg} / \mathrm{ml})$ in $50 \mathrm{mM}$ Tris (pH7.4) with $0.001 \% \mathrm{H}_{2} \mathrm{O}_{2}$. Control experiments consisted of incubation with pre-immune rabbit serum. To investigate the effects of postmortem delay and fixation on the levels of mTor immunoreactivity, preliminary studies were performed in a subset of cases $(n=5)$ with postmortem delay ranging from 4 to $48 \mathrm{~h}$. In addition, double immunolabeling studies were performed as previously described (Spencer et al. 2009) to determine the cellular localization of the autophagy markers. For this purpose, vibratome sections from the young and aged HIV+ and HIVE+ cases as well as of the non-tg and gp120 tg mice were immunostained with antibodies against the neuronal marker MAP2 (mouse monoclonal) and antibodies against either LC3, mTor, or Cathepsin-D (rabbit polyclonal). Sections were then reacted with secondary antibodies tagged with FITC to detect MAP2 and mTor and with the tyramide Red amplification system (Perkin-Elmer) to detect Cathepsin-D. Conversely for the experiments analyzing LC3, this autophagy marker was detected with FITC while MAP2 was detected with the tyramide Red amplification system (Perkin-Elmer). Sections were mounted on superfrost slides (Fisher) and coverslipped with media containing DAPI. Double-immunolabeled sections were imaged with the laser scanning confocal microscope as described below.

Immunostained sections were imaged with a digital Olympus microscope and assessment of levels of GFAP, Iba1, beclin-1, Cathepsin-D, and mTor immunoreactivity was performed utilizing the Image-Pro Plus program (Media Cybernetics, Silver Spring, MD, USA). For each case, a total of three sections (10 images per section) were analyzed in order to estimate the average number of immunolabeled cells per unit area (square millimeter) and the average intensity of the immunostaining (corrected optical density).

For confocal images (LC3 and MAP2), all sections were processed simultaneously under the same conditions and experiments were performed twice for reproducibility. Sections were imaged with a Zeiss $63 \times$ (N.A. 1.4) objective on an Axiovert 35 microscope (Zeiss, Germany) with an attached MRC1024 laser scanning confocal microscope system (BioRad, Hercules, CA, USA).

Analysis of neurodegeneration

Neuronal structural integrity was evaluated as previously described (Rockenstein et al. 2005a, b). In brief, blindcoded, $40 \mu \mathrm{m}$ thick microtome sections from human and mouse brains fixed in $4 \%$ paraformaldehyde were immunolabeled with mouse monoclonal antibodies against MAP2 (1:200). After overnight incubation, sections were incubated with fluorescein isothiocyanate-conjugated secondary antibodies (1:75; Vector Laboratories, Burlingame, CA, USA), transferred to SuperFrost slides (Fisher Scientific, Tustin, CA, USA), and mounted under glass coverslips with antifading medium (Vector Laboratories). All sections were processed under the same standardized conditions. The immunolabeled blind-coded sections were serially imaged with a laser scanning confocal microscope (MRC-1024; 
Bio-Rad) and analyzed with ImageJ v1.43 software (NIH, Bethesda, MD, USA), as previously described (Crews et al. 2010). For each mouse, a total of three sections were analyzed; for each section, four fields in the frontal cortex and hippocampus were examined. Results were expressed as percent area of the neuropil occupied by immunoreactive signal. All sections were processed under the same standardized conditions. Immunostained sections were imaged with a digital Olympus microscope and the Image-Pro Plus program (version 4.5.1, Media Cybernetics).

\section{Statistical analysis}

All the analyses were conducted on blind-coded samples. After the results were obtained, the code was broken and data were analyzed with the StatView program (SAS Institute, Inc., Cary, NC, USA). Comparisons among groups were performed with one-way ANOVA, unpaired Student's $t$ test and Chi-square analysis. All results were expressed as mean \pm SEM. The differences were considered to be significant if $p$ values were $<0.05$.

\section{Role of the funding source}

The funding source had no role in the study design, data collection, data analysis, data interpretation or writing of this report. The corresponding author had full access to all the data and had final responsibility for the decision to submit the paper for publication.

\section{Results}

Clinical and neuropathological characteristics of young and aged donors with and without HIVE

Before analyzing autophagy protein levels, we first meticulously collected and characterized clinical and neuropathological aspects of the young and aged HIV+ cohort. For this purpose, at first, a total of 83 autopsy cases were analyzed ( $n=50$ young and $n=33$ aged). In order to assess relevant differences between postmortem brain samples from young and aged HIV patients, we characterized the cohorts by brain pathology, CD4+ cell count, viral load, and neuropsychological impairment status. Table 1 demonstrates both young and aged cohorts were predominantly male and $40 \%$ of each cohort had normal brain pathology (Table 1). Only one (2\%) of the young cases showed Alzheimer type II gliosis, whereas six (18\%) of the 33 aged patients showed Alzheimer type II gliosis (Table 1). Conversely, one (3\%) of the aged patients presented microglial nodule encephalitis, while microglial nodule encephalitis was present in six $(12 \%)$ of the young patients (Table 1). Seventeen (33\%) of young cases showed HIVE versus eight (24\%) among the aged patients (Table 1). Of the 83 autopsy cases, complete neurovirological and neurological analysis was available in 55 cases ( $n=31$ younger and $n=24$ aged). Further analyses revealed that young cases had significantly $(p<0.05)$ lower $\mathrm{CD} 4+$ cell counts compared to aged patients, and significantly $(p<0.05)$ higher plasma VL (Table 2). CSF VL was equivalent between young and aged groups (Table 2). Assessment of neuropsychological impairment showed that nine (18\%) of the young group suffered HAD, and another nine (18\%) suffered minor cognitive motor deficits, whereas only one $(3 \%)$ and two $(6 \%)$ donors of the aged group suffered from these afflictions, respectively (Table 2). Twenty percent of cases from each group presented NPI-other $(\mathrm{O})$, and the aged group had two NPI-unknown (U) cases (Table 2). Five of the young patients were unable to complete assessment and two were normal, while four of the aged patients were unable to complete assessment and six were normal (Table 2). These data indicate stark differences in the pathology and neuropsychological state between young and aged cases in this HIV+ cohort.

HIV capsid protein, p24, levels are increased in aged and neuropsychological impaired patients

To further characterize neuropathology among the young and aged cohorts, p24 levels in postmortem brain tissue from young and aged HIV patients were measured by ELISA and correlated to neuropathology and neuropsychological impairment. p24 levels were statistically equal between young and aged HIV patients (Fig. 1a). For this analysis, tissues were available for all 83 cases, of them $n=50$ young $(n=33 \mathrm{HIV}+$ and $n=17 \mathrm{HIVE})$ and $n=33$ aged ( $n=23 \mathrm{HIV}+$ and $n=10 \mathrm{HIVE}$ ). $\mathrm{p} 24$ levels were increased in postmortem tissues from young and aged HIVE patients compared to age-matched HIV controls (Fig. 1b, $p<0.05$ and $p<0.001$, respectively). p24 levels in postmortem tissues from aged HIVE patients were significantly increased compared to young HIVE patients (Fig. 1b, $p<0.001$ ). Similarly, p24 levels are increased in young and aged patients with any neuropsychological impairment compared to age-matched HIV controls (Fig. 1c). p24 levels were highest in the aged patients with neuropsychological impairment (Fig. 1c). Data represent analysis of the entire cohort of HIV+ and HIVE donor brains.

Neuroinflammation and neuropathology were increased in postmortem brains from aged HIVE patients

Next, we measured levels of inflammatory and neuronal markers by immunohistochemical analysis in a subgroup of $n=29$ postmortem cases, $n=15$ young ( $n=7 \mathrm{HIV}+$ and 
Table 2 CD4+ cell count, plasma VL, presence of neuropsychological impairment, and CSF VL in the young and aged HIV + cohort

\begin{tabular}{|c|c|c|c|c|c|}
\hline Group & CD4* & Log plasma VL* & Log CSF VL & NPI & $\mathrm{ARV}+/-$ \\
\hline Under 50 (young) & $70.2 \pm 151.9(n=29)$ & $4.53 \pm 1.39(n=29)$ & $3.14 \pm 1.35(n=30)$ & $\begin{array}{l}9 \text { HAD, } 9 \text { MCMD, } 3 \text { NPI, } 10 \text { NPI-O, } \\
5 \text { unable, } 2 \text { normal }\end{array}$ & $16 / 15$ \\
\hline 50 and older (aged) & $241.2 \pm 325.4(n=25)$ & $3.64 \pm 1.70(n=23)$ & $2.64 \pm 1.25(n=21)$ & $\begin{array}{l}1 \text { HAD, } 2 \text { MCMD, } 3 \text { NPI, } 7 \text { NPI-O, } \\
2 \text { NPI-U, } 4 \text { unable, } 6 \text { normal }\end{array}$ & $14 / 10$ \\
\hline
\end{tabular}

$n$ number of independent donors, $M C M D$ minor cognitive motor deficits

$* p<0.05$

$n=8 \mathrm{HIVE}$ ) and $n=14$ aged ( $n=8 \mathrm{HIV}+$ and $n=6 \mathrm{HIVE})$. Vibratome sections from paraformaldehyde fixed frontal cortex were used. Inflammatory markers GFAP and Iba-1 were increased, while MAP2 (somato-dendritic marker) immunostaining was decreased in brain tissue from aged HIVE patients compared to young HIVE patients (Fig. 2ac). Astroglial marker, GFAP immunoreativity, and signal were elevated in young and aged HIVE tissues versus young and aged HIV+ samples; however, GFAP signal was most intense in tissues from aged HIVE patients (Fig. 2a). The microglial marker, Iba-1, signal intensity was increased in brain tissues of young and aged HIVE patients compared to HIV+ patients from both groups, with cells from HIVE tissues having more extended processes in greater numbers (Fig. 2b). MAP2 neuronal marker immunoreactivity was opposite that of GFAP and Iba-1 staining; young and aged HIVE tissues had reduced MAP2 signal compared to young and aged HIVE tissues (Fig. 2c). Furthermore, MAP2 staining in aged HIVE tissues was the most punctate and discontinuous, as indicated by the white arrows (Fig. 2c). GFAP and Iba-1 optical density in HIVE samples was significantly $(p<0.001)$ increased compared to age-matched HIV + samples (Fig. 2d-e). GFAP optical density was significantly ( $p<$ 0.05 ) increased in aged HIVE samples compared to young HIVE samples (Fig. 2d). Quantification of MAP2 neuronal marker indicated area of the neuropil stained decreased from $26 \%$ (in young $\mathrm{HIV}+$ patients) to $20 \%$ (area of neuropil in young HIVE patients; $p<0.01)$. MAP2 levels were decreased from $24 \%$ (area of the neuropil in aged HIV+ patients) to $16 \%$ (area of neuropil in aged HIVE patients; Fig. 2e, $p<0.001)$. MAP2 (16\% of the neuropil) levels in aged HIVE samples were significantly $(p<0.05)$ reduced compared to young HIVE samples (21\% of neuropil).

Autophagy markers are reduced in aged HIVE patients compared to young HIVE patients

To analyze autophagy pathway activity, aged and young HIV+ and HIVE brain beclin-1, cathepsin-D, LC3, and mTor were analyzed immunohistochemistry (Fig. 3a-h). Immunohistochemical analysis of pyramidal neurons in layers II-III and V of the midfrontal cortex from young and aged HIV+ and HIVE patients showed beclin-1, cathepsin-D, and LC-3 levels were increased in young HIVE versus young HIV+ samples; however, levels of all three autophagy markers were decreased in aged HIVE versus aged HIV + brains (Fig. 3a-c). For each case analysis of beclin-1, cathepsin-D and LC-3 immunoreactivity was performed in comparable layers of the neocortex to assure consistent comparisons. The black box inset denotes area of high cathepsin-D immunoreactivity in young HIV+ patients (Fig. 3b). White arrows indicate LC3 staining of autophagosomes in neurons (Fig. 3c). Levels of mTor were moderate in young HIV+ and HIVE brains, but were increased in a

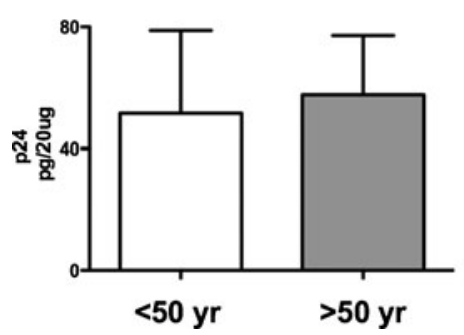

b

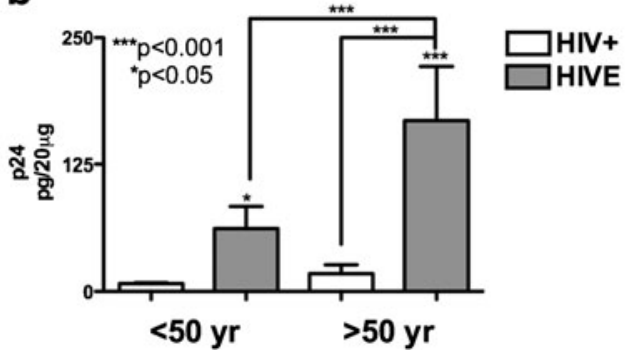

C

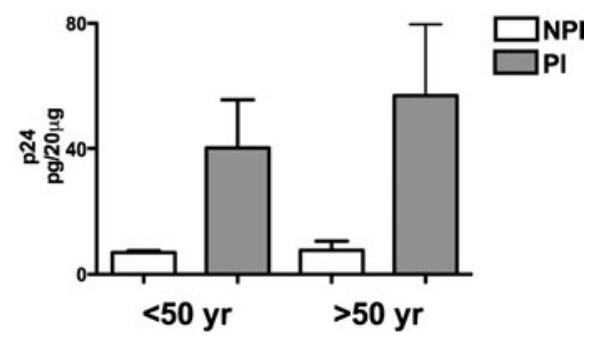

Fig. 1 p24 levels in postmortem samples from young and aged HIVE patients and in patients with neuropsychological impairment. a p24 protein levels measured by ELISA from postmortem brain samples from young and aged HIV+ patients. b p24 protein levels in postmortem samples from young and aged cases categorized by HIV+ and HIVE. c Compares young and aged HIV+ patients further categorized as no psychological impairment (NPI) or presence of any psychological impairment (PI). Statistical significance $(* p<0.05, * * * p<0.001$, one-way ANOVA, post hoc Fisher's test) compared to HIV+. These data represent compilations of the entire cohort of HIV + and HIVE donor brains (total $n=83$ ), of them $n=50$ young ( $n=33 \mathrm{HIV}+$ and $n=17$ HIVE) and $n=33$ aged $(n=23 \mathrm{HIV}+$ and $n=10 \mathrm{HIVE})$ 


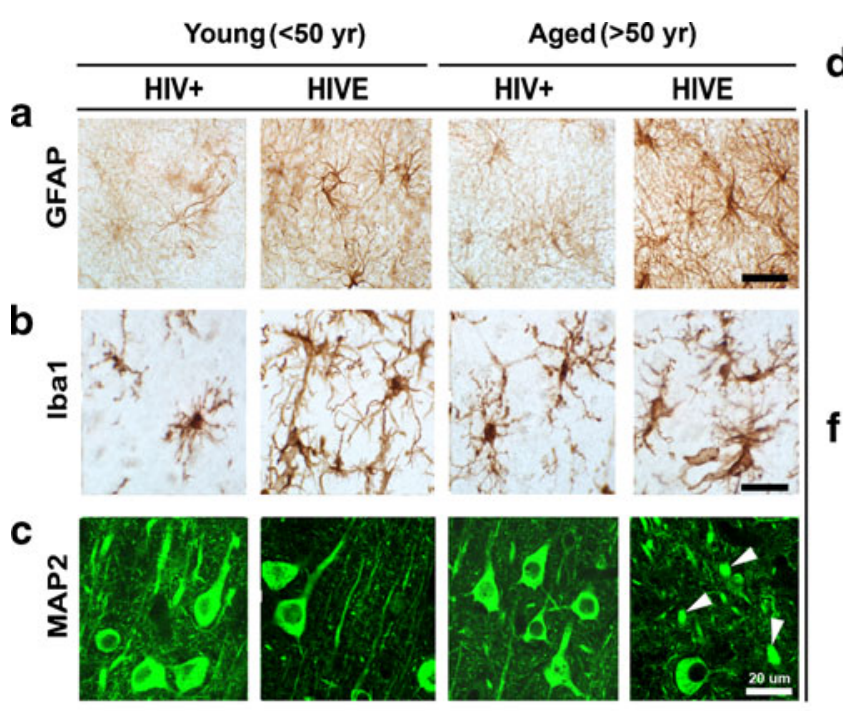

Fig. 2 Immunohistochemical localization of GFAP, Iba1, and MAP2 in postmortem brain samples from young and aged HIV+ and HIVE patients. a-c GFAP, Iba1, and MAP2 signal localization in young aged HIVE patients. d GFAP optical density in brains from young and aged HIV+ and HIVE patients. e Iba-1 optical density in brains from young

aged HIV+ and HIVE brains (Fig. 3d). Beclin-1 optical density is significantly $(p<0.001)$ increased in young HIVE compared to young HIV+ samples; however, beclin1 optical density in aged HIVE samples is significantly $(p<$ 0.001) reduced compared to levels in young HIVE samples (Fig. 3e). Cathepsin-D optical density levels were significantly increased in young HIVE compared to levels in young HIV+ brains and similar to beclin-1 levels, cathepsin-D levels in aged brains were significantly $(p<$ 0.01) reduced compared to young HIVE samples (Fig. 3f). Quantification of LC3 confocal image pixel intensity revealed LC3 levels in young HIVE brains are significantly $(p<0.001)$ reduced compared to levels young HIV+ brains (Fig. 3g). Aged HIV+ and HIVE brain LC3 levels are equivalent but significantly $(p<0.001)$ reduced compared to young HIVE brain LC3 levels. Quantification of mTor optical density reveals young HIV+ and HIVE brains have similar mTor expression; however, mTor levels in aged HIV+ and HIVE were increased compared to young samples (Fig. 3h). Furthermore, mTor levels in aged HIVE samples were significantly $(p<0.01)$ higher than levels in aged HIV+ samples (Fig. 3h). To confirm that the alterations in markers of autophagy were in pyramidal neurons of layers II-III and V, double labeling and confocal microscopy studies were performed. Both in the young and aged HIV+ cases, most (approximately $90 \%$ ) of the cathepsin-D, LC3, and mTor immunoreactive granules in the cytoplasm of cells were observed in MAP2 immunoreactive neurons (Fig. 4a).

To corroborate immunohistochemical data beclin-1, LC3, mTor, and actin were measured by immunoblot in postmortem

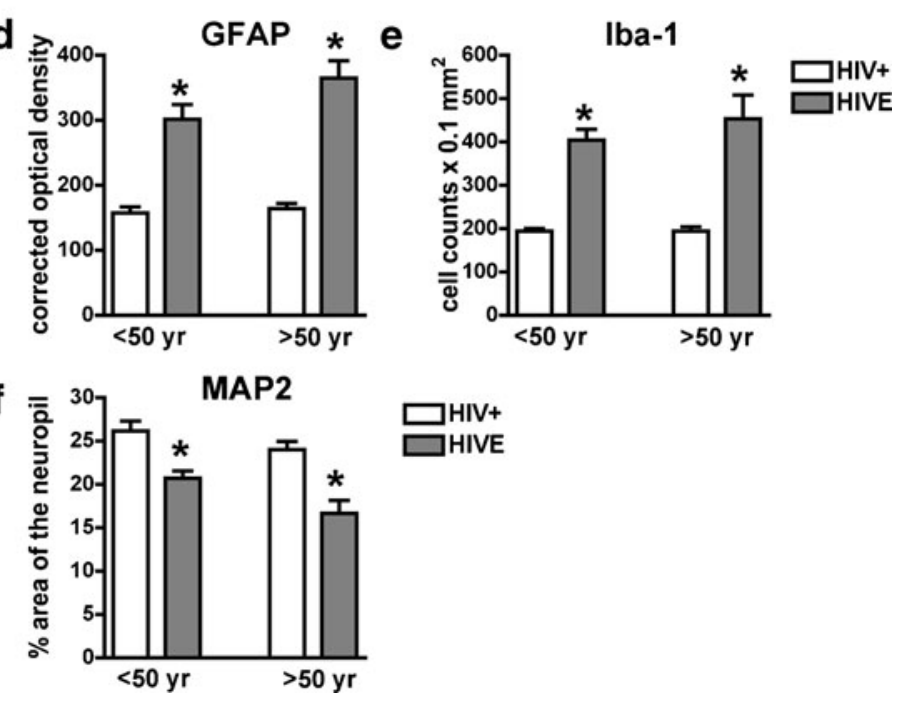

and aged HIV+ and HIVE patients. f MAP2 signal as percent of the neuropil stained. Arrows indicate fragmented MAP2 staining and truncated axons/soma. A total of $n=29$ postmortem cases were analyzed, of them $n=15$ young $(n=7 \mathrm{HIV}+$ and $n=8 \mathrm{HIVE})$ and $n=14$ aged $(n=$ $8 \mathrm{HIV}+$ and $n=6$ HIVE)

brain samples from aged and young HIV+ and HIVE patients (Fig. 5a-c). Beclin-1 and LC3 signals were increased in young HIVE compared to young HIV+ samples; however, beclin-1 and LC3 signals were decreased in aged HIVE compared to aged HIV+ samples (Fig. 5a). Analysis of band density revealed that young HIVE beclin-1 levels were increased 2.5 -fold compared to young HIV+ samples $(p<0.05)$; however, aged HIVE sample beclin-1 levels were decreased by $60 \%$ compared to aged HIV+ samples (Fig. 5b, $p<0.05$ ). Similarly, LC3 band density analysis revealed that levels were increased in young HIVE compared to young HIV+ patients $(p<0.05)$, yet aged HIVE LC3 levels were significantly reduced $(p<0.05)$ compared to aged HIV+ LC3 levels (Fig. 5 c).

Autophagy markers are reduced in aged gp120-tg mice; lentivirus delivery of beclin-1 restores autophagy marker expression

To investigate alterations in the autophagy pathway in an experimental model of HIV protein neurotoxicity, immunochemical analysis was performed in aged (12 months) gp120 tg and non-tg mice. Immunohistochemical analysis showed that compared to aged non-tg mice, levels of beclin1 , cathepsin-D, and LC3 are reduced and mTor is increased in brains of aged gp120 tg mice. Lentiviral-mediated delivery of beclin-1 via stereotaxic injection to the temporal cortex of gp120 tg mice increased beclin-1, cathepsin-D, and LC3 levels in aged non-tg and aged gp120 tg mice (Fig. 6a-c). Beclin-1 delivery significantly $(p<0.05)$ reduced mTor levels in aged gp120 tg mice (Fig. 6d). Quantification of 


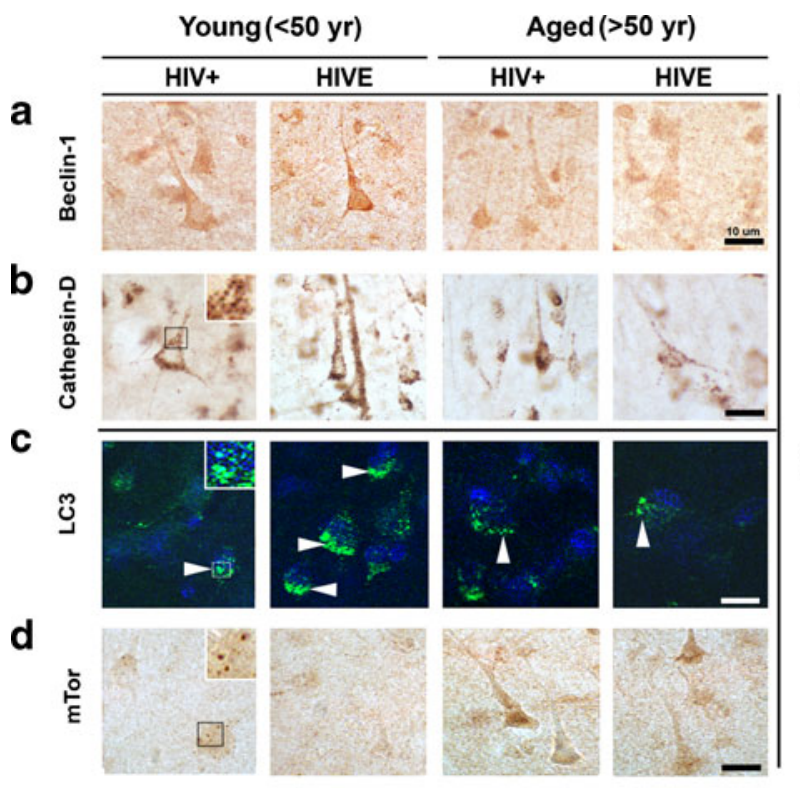

Fig. 3 Immunohistochemical comparisons of autophagy markers in young vs aged HIV+ and HIVE patients. Postmortem brain samples were immunostained for beclin-1, cathepsin-D, LC3, and mTor and analyzed with confocal or bright-field microscopy. a-d Beclin-1, cathepsin-D, LC3, and mTor immunoreactivity in young and aged HIV+ and HIVE brain tissues. The black box inset (b) denotes area of high Cathepsin-D immunoreactivity in young HIV+ patients. White

autophagy marker optical density or pixel intensity showed beclin-1, cathepsin-D, and LC3 levels were significantly $(p<0.05)$ reduced in aged gp120 tg brains compared to levels in aged non-tg control mice brains (Fig. 6e-g). Levels of mTor immunoreactivity were increased in aged gp120 tg mice compared to aged non-tg mice, and this was reversed by LVmediated beclin-1 delivery (Fig. 6h). To confirm that the

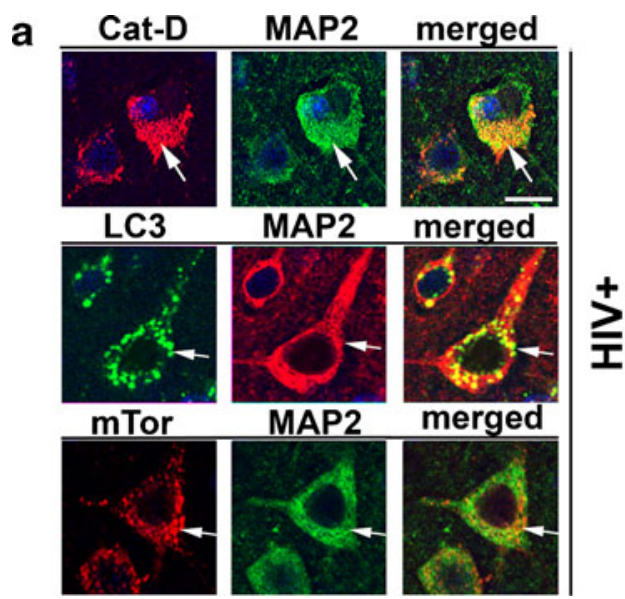

Fig. 4 Double immunolabeling studies for autophagy and neuronal markers in HIV+ and gp120 tg mice. a Representative images obtained with the laser confocal microscopy. MAP2 immunolabeled neurons in layer $\mathrm{V}$ of the frontal cortex from an aged patient with HIV+ showing the colocalization of Cathepsin D, LC3, and mTor with the neuronal marker. Arrows point to the granular structures in the cytoplasm of

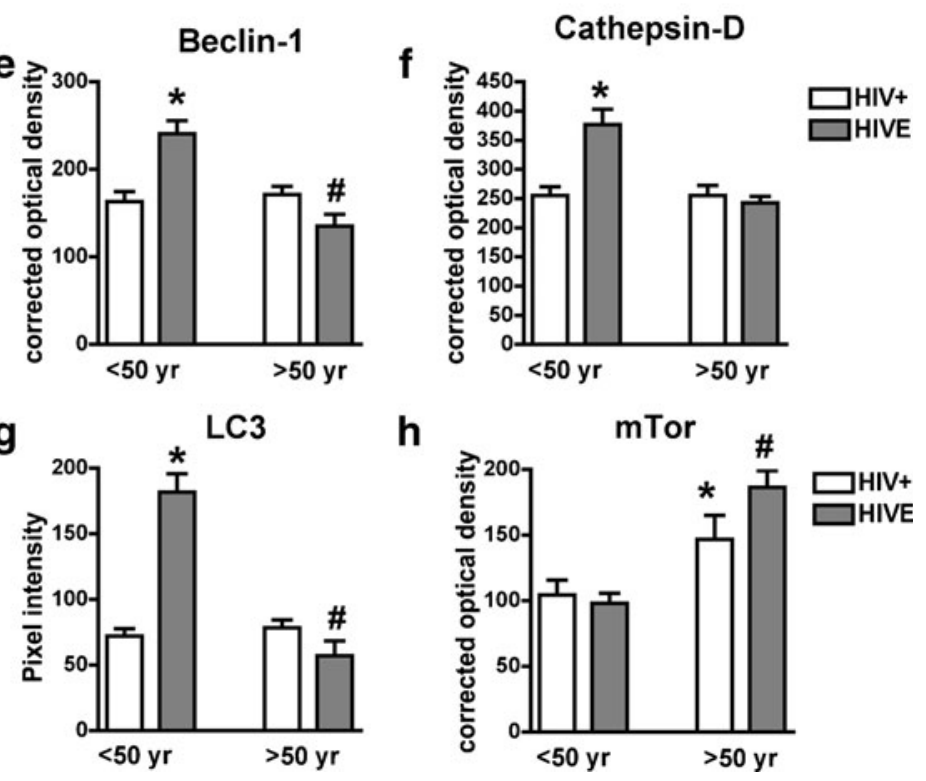

arrows in $\mathbf{c}$ indicate LC3-positive autophagosome localization. Semiquantitative analysis of $\mathbf{e}$ beclin- $1, \mathbf{f}$ cathepsin-D, $\mathbf{g}$ LC 3 , and $\mathbf{h}$ mTor immunoreactivity. Statistical significance $\left({ }^{*} p<0.05\right.$, one-way ANOVA, post hoc Fisher's test) compared to HIV+. A total of $n=29$ postmortem cases were analyzed, of them $n=15$ young $(n=7 \mathrm{HIV}+$ and $n=8 \mathrm{HIVE})$ and $n=14$ aged ( $n=8 \mathrm{HIV}+$ and $n=6 \mathrm{HIVE})$

effects of the lentivirus on markers of autophagy are in pyramidal neurons, double labeling and confocal microscopy studies were performed. Both in the non-tg and gp120 tg mice treated with the LV-beclin1 the majority (approximately $90 \%$ ) of the cathepsin-D, LC3, and mTor immunoreactive cells were localized to MAP2 immunostained cells (Fig. 4a).

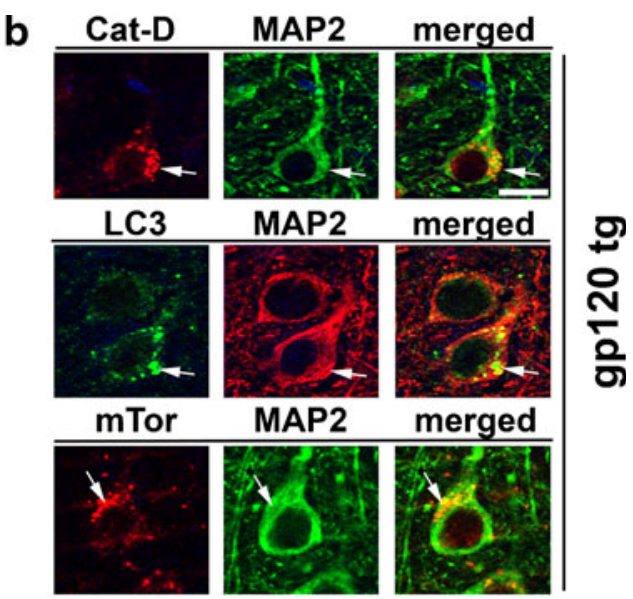

neurons representing lysosomes and autophagolysosomes. Bar $10 \mu \mathrm{m}$. b Representative laser confocal microscopy images from an aged gp120 tg mouse treated with LV-beclin-1. MAP2 immunolabeled neurons in layer $\mathrm{V}$ of the frontal cortex co-localized with cathepsin D, LC3, and mTor. Arrows granular structures in the cytoplasm of neurons representing lysosomes and autophagolysosomes. Bar $10 \mu \mathrm{m}$ 

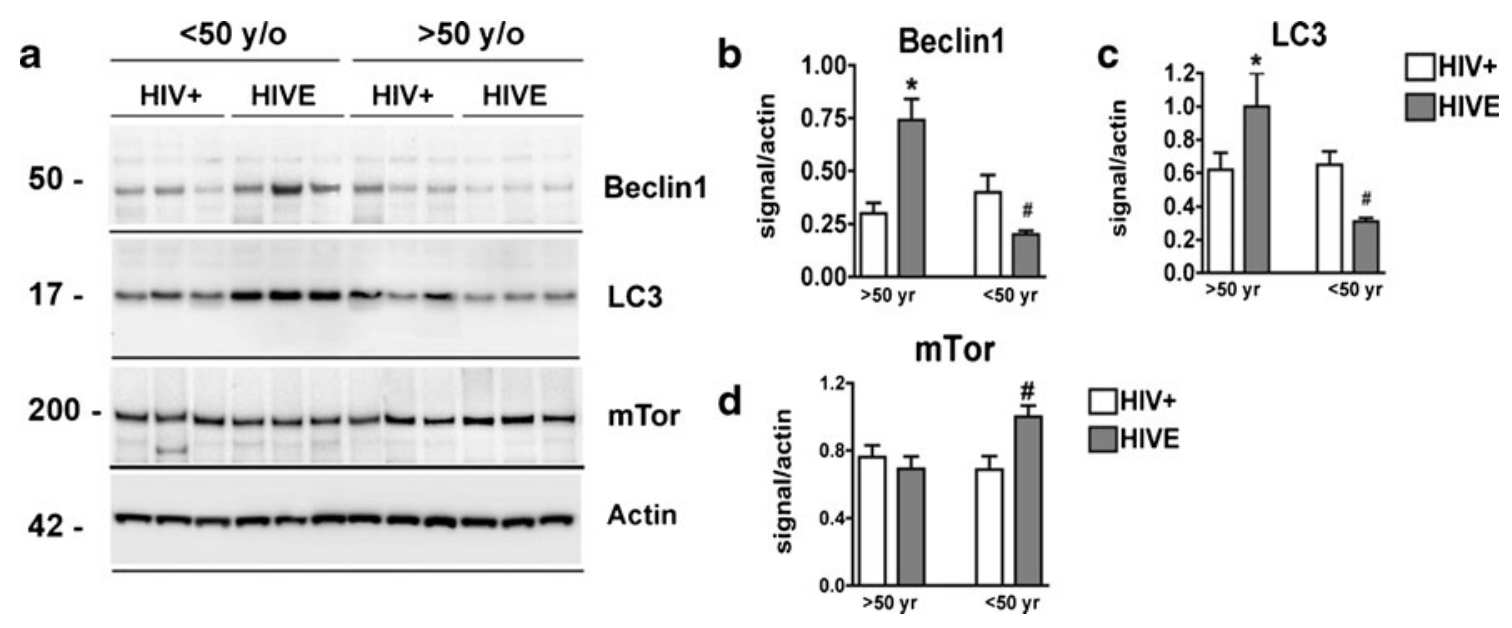

Fig. 5 Immunoblot comparisons of autophagy markers in brains of young vs aged HIV+ and HIVE postmortem tissues. a Immunoblot image of a representative subset of samples labeled for beclin-1, LC3 mTorb and Actin. b-d Beclin-1, LC3, and mTor band intensity normalized to actin expression, respectively, from young and aged HIV+

LV-mediated beclin-1 delivery reduces neuroinflammation and neurodegeneration in aged gp120 tg mice brains

Overexpression of beclin-1 from the lentivirus reduced astrogliosis and microgliosis markers and neurodegeneration in gp120 tg mice. Immunohistochemical analyses of gp120 tg mice brains show GFAP and Ibal staining was increased while MAP2 staining was decreased compared to

and HIVE patients. For statistics, a total of $n=29$ postmortem cases were analyzed, of them $n=15$ young ( $n=7 \mathrm{HIV}+$ and $n=8 \mathrm{HIVE})$ and $n=14$ aged $(n=8 \mathrm{HIV}+$ and $n=6 \mathrm{HIVE})$. Statistical significance $\left({ }^{*} p<\right.$ 0.05 , one-way ANOVA, post hoc Fisher's test) compared to HIV+

control non-tg mice (Fig. 7a-c). GFAP positive cells were more numerous with extended processes and displayed more intense GFAP signal (Fig. 7a). Similarly, Ibal signal was increased in gp120 tg mouse brains compared to non-tg control mice (Fig. 7b). gp120 tg mouse brains expressed reduced levels of MAP2 in a more punctate and discontinuous pattern (Fig. 7c). Compared with the LV-control, LVbeclin-1 injection reduced GFAP and Iba1 signal increased
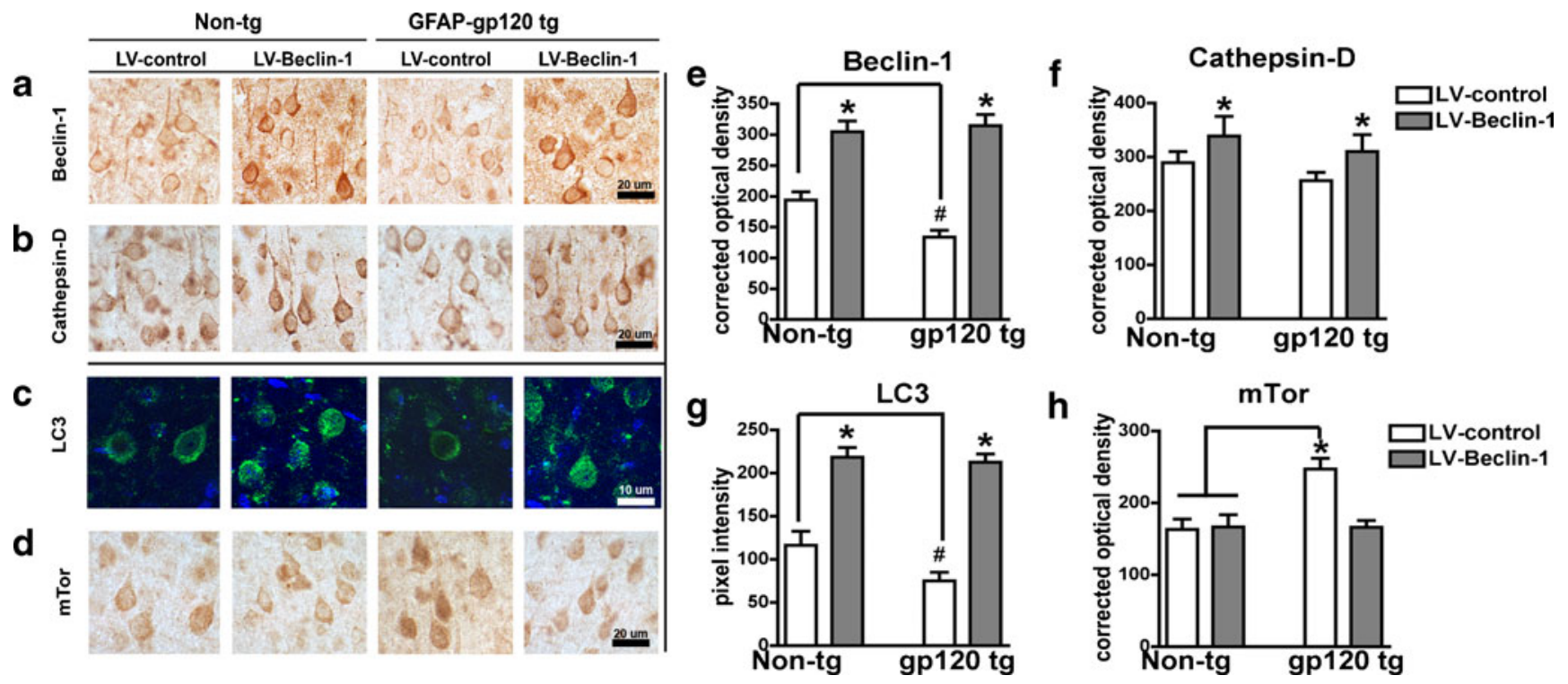

Fig. 6 Lentivirus-mediated delivery of beclin-1 to aged gp120 tg mice increases autophagy markers. Immunohistochemical and confocal analysis 3 months after injection. a Beclin-1 immunoreactivity in non-tg and gp120 tg mice that were injected with LV-control and LVbeclin-1. b Cathepsin-D immunoreactivity in non-tg and gp120 tg mice that were injected with LV-control and LV-beclin-1. c LC3 immunoreactivity in non-tg and gp120 tg mice that were injected with LV-control and LV-beclin-1. d mTor immunoreactivity in non-tg and gp120 tg mice that were injected with LV-control and LV-beclin-1. Semiquantitative levels of $\mathbf{e}$ beclin-1, $\mathbf{f}$ cathepsin-D, $\mathbf{g}$ LC3, and $\mathbf{h}$ mTor illustrated as optical density (e, f, and $\mathbf{h})$ or pixel intensity (g). Samples were further stained with DAPI to visualize nuclei (blue). Statistical significance $(* p<0.05$, one-way ANOVA, post hoc Fisher's test) compared to non-tg controls. All panels are from the frontoparietal cortex of 12month-old mice, a total of $n=20$ mice ( $n=5$ per group) were included for the study 
and normalized MAP2 staining in gp120 tg mouse brains (Fig. 7a-c). Quantification of GFAP, Iba1, and MAP2 immunoreactivity corroborated evidence that LV-beclin-1 reduced astrogliosis, microgliosis, and neurodegeneration in GFAP gp120 tg mice (Fig. 7d-f). GFAP optical density was equivalent between LV-control and LV-beclin-1 treated nontg mice; however, GFAP optical density was significantly $(p<0.05$, twofold) elevated in gp120 tg mice brains compared to non-tg mice (Fig. 7d). LV-beclin-1 significantly $(p<0.05,-30 \%)$ reduced GFAP optical density in gp120 tg mice brains (Fig. 7d). Ibal staining was significantly $(p<0.05)$ elevated in gp120 tg mice compared to non-tg mice; however, LV-beclin-1 significantly $(p<0.05)$ reduced Iba1 staining in fp120 tg mouse brains (Fig. 7e). The area of the neuropil stained by MAP2 was significantly $(p<0.05$, $-25 \%)$ reduced in gp120 tg mouse brains compared to nontg mice; LV-beclin-1 restored gp120 tg brain MAP2 staining to levels of non-tg mice (Fig. 7f).

\section{Discussion}

In the current study, we show for the first time differential levels of autophagy proteins in postmortem brain tissue samples from aged HIVE and young HIVE patients. While the young HIVE group display increased autophagy markers, the aged HIVE group showed reduced autophagy pathway proteins. Viral protein and inflammatory marker levels were increased while autophagy proteins beclin-1,
LC3 and the neuronal marker MAP2 were reduced in HIVE brain tissues from aged donors compared to those from young donors. Similarly, analysis of aged gp120 tg mouse brains showed reduced autophagy marker expression and increased neurodegeneration compared to aged non-tg mice. LV-beclin-1 gene transfer restored autophagy markers and reduced neuroinflammation and neurodegeneration in aged gp120 tg mouse brains. Previous studies have shown that HIV can alter the autophagy pathway, but these studies show possible reduced autophagy function in aged HIVE patients and increased inflammation markers accompanied with simplified neuronal synaptic complexity compared to young HIVE donors. Furthermore, LV-mediated beclin-1 gene transfer restores autophagy function and reduces neurodegeneration in aged gp120 tg mice. HIV infection in young patients may differ markedly to that in aged patients with respect to autophagy and neuronal injury; these data corroborate evidence that HIV infection may exacerbate consequences of normal aging and may provide a potential therapy for aged HAND patients.

The present studies are consistent with recent findings that suggest the autophagy pathway is dysregulated during AD, PD, and HIV (Ebrahimi-Fakhari et al. 2011; Pickford et al. 2008; Zhou et al. 2011); however, this is the first report of distinct differences in autophagy marker expression among young and aged HIVE patients. A survey of HIV patients showed overall autophagy markers are increased in postmortem samples from HIV-infected individuals (Zhou et al. 2011). By further categorizing patients according to

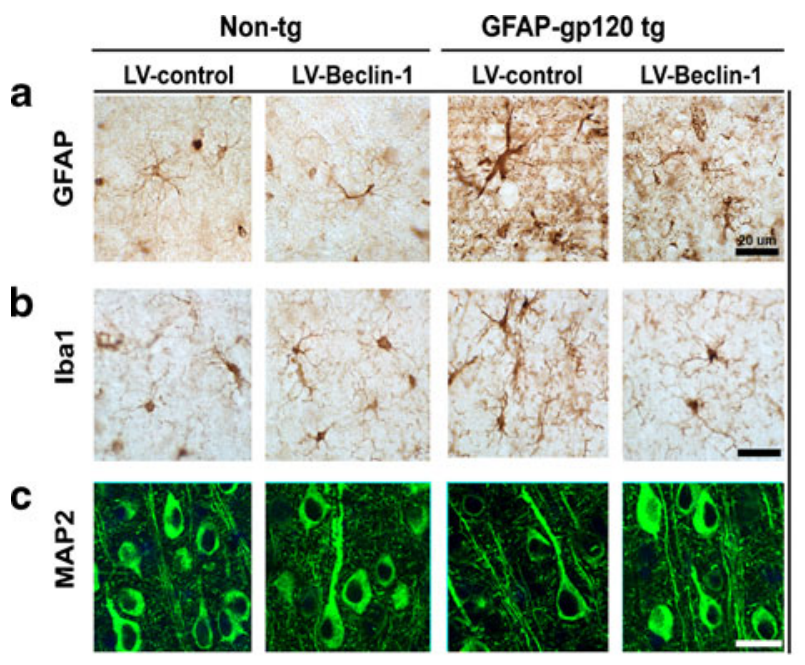

Fig. 7 Lentivirus-mediated delivery of beclin-1 to aged gp120 tg mice ameliorates neurodegenerative pathology. Non-tg and gp120 mice were injected with LV-control or LV-beclin-1 and after 3 months of the injection, mice were immunostained and analyzed with confocal microscopy or bright-field microscopy. a-c Effects of LV-beclin-1 on patterns of a GFAP, b Iba1, and c MAP2 immunoreactivity. d

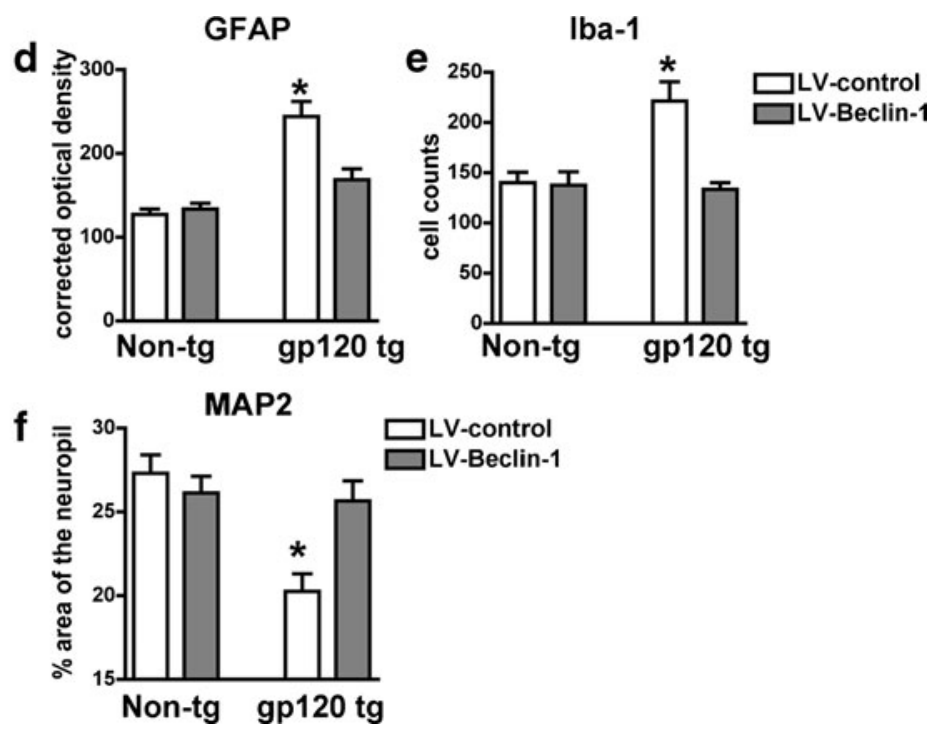

Semiquantitative analysis of GFAP optical density. e Number of Iba$1+$ cells. f MAP2 immunoreactivity illustrated as percent area of the neuropil. Statistical significance $(* p<0.05$, one-way ANOVA, post hoc Fisher's test) compared to non-tg controls. All panels are from the frontoparietal cortex of 12-month-old mice, a total of $n=20$ mice $(n=5$ per group) were included for the study 
age and HIVE status, the current studies revealed distinct differences in aged and young HIVE brains. These differences in autophagy function among young and aged HIVE patients may contribute to the growing list of chronic comorbidities among aged HIV patients. The differences observed in brains from deceased young versus aged HIVE patients suggest that two distinct types of infection may be responsible for the differences observed between young and aged HIVE patients: (1) viremia is robust and infiltrates the CNS leading to early neural complications and death (young) or (2) viremia is subdued throughout infection, the CNS is not dramatically affected early on, yet longterm infection gradually increases neuroinflammation and neurodegeneration (aged). HIV patients that live over 50 years may harbor a low but chronic viral burden that can limit normal autophagy function and lead to proteinopathies such as seen in $\mathrm{AD}$ and $\mathrm{PD}$. Another alternative is that HIV infection progresses similarly in most patients but some patients escape the battery of opportunistic infections to live a longer life. The compensatory autophagy response seen in young patients may be meant to clear excessive toxic molecule build up until the system is overwhelmed and the molecular recycling system fails. Reduced autophagy marker levels detected in aged HIVE samples may represent less viable cells with reduced capacity to perform normal physiological processes, such as autophagy. Consistent with this notion, $A \beta$ expression correlates with age in postmortem samples from HIVE patients, and in the second scenario this may be a natural occurrence of most chronic HIV infections (Achim et al. 2009; Khanlou et al. 2009). In either case, understanding how HIV affects neuronal autophagy may lead to therapies that slow down neurodegeneration. Importantly, neither of these scenarios considers those individuals who contract HIV infection after turning 50, for which alternative patterns of disease have been reported (Erlandson et al. 2012). Additional studies using samples from large cohorts of HIV patients combined with animal models and cellular-based studies will prove valuable in dissecting the complications of aging with neuroAIDS.

Beclin-1 and LC3 are essential proteins in the autophagy pathway, and interference at either level may result in cellular toxicity (Kragh et al. 2012). Beclin-1 mediates autophagosome nucleation and LC3 is an integral autophagy protein that facilitates autophagosome elongation and closure and may also be involved in disease (Dinkins et al. 2010; Gannage et al. 2010; Kyei et al. 2009). Despite increased autophagy machinery, HIV patients have increased $\mathrm{A} \beta$ and $\alpha$-synuclein accumulation in the brain (Achim et al. 2009; Khanlou et al. 2009). These and other reports suggest that dysfunctional autophagy is associated with neurodegenerative diseases and may exacerbate problems associated with HIV infection of the CNS. In this context, it may be possible to reintroduce functional autophagy by gene transfer to ameliorate HIVE phenotypes.

It was recently reported that HIV-1 infection inhibits autophagy pathways in monocytes, but no direct effect on neurons has been shown (Van Grol et al. 2010). Kyei et al. showed that the HIV-1 protein Nef interacts with autophagy pathways in macrophages (Kyei et al. 2009). In subsequent findings, groups have shown that HIV-1 may highjack the autophagy pathway to promote replication (Gregoire et al. 2011; Killian 2012). Despite these advances, it is not known if HIV directly or indirectly affects neuronal autophagy and ultimately contributes to neurodegeneration. Our current studies show aged HIVE patients express increased neuroinflammatory markers and reduced neuronal markers, indicating progressed neurodegeneration, and loss of synaptic processes may be associated with decreased autophagyrelated proteins (beclin-1 and LC3). The gp120 tg mouse serves as a model for HIV-1-protein mediated neurotoxicity and the mice present neuropathology and behavioral deficits similar to those seen in HAND patients (Toggas et al. 1994). Furthermore, in the $\alpha$-syn tg mouse model for PD, LVmediated delivery of beclin-1 to the CNS reversed neuropathology and reduced the accumulation of $\alpha$-syn (Spencer et al. 2009). The current studies further support the hypothesis that proteinopathies may be due to dysfunctional autophagy and that normal molecular recycling may be restored via LVmediated beclin-1 gene transfer. Indeed, LV-beclin-1 ameliorated astrogliosis, microgliosis, and neurodegeneration in the gp120 tg mouse model and may serve as a therapy for aged HAND patients.

Impetus has been placed on understanding how aging may exacerbate HAND. Healthy individuals $>65$ are designated elderly by the Centers for Disease Control, but HIV infected individuals are designated "aged" HIV patients at $>50$, due to progressed signs of aging. It is predicted that by 2015 , over $50 \%$ of AIDS cases in the USA, and $15 \%$ of newly diagnosed cases will be $>50$ (Erlandson et al. 2012; Watkins and Treisman 2012). Reports have demonstrated that aged HIV patients have increased risk of severe depression and cognitive impairment, less time between infection and AIDS diagnosis and reduced T-lymphocyte proliferation (Watkins and Treisman 2012). Further studies are needed to characterize and combat HIV in this particularly vulnerable group. Our data support the hypothesis that HIV exacerbates the effects of aging and implicate dysregulated autophagy as a possible cause of HAND.

Studies on mechanisms of HIV pathogenesis in aged patients are lacking; aging with HIV is a relatively novel problem. Most studies consider neuroAIDS with respect to the HIV-infected population as a whole, yet physicians and the CDC note stark differences in the progression of disease between young and aged groups (Erlandson et al. 2012; Watkins and Treisman 2012). In an effort to understand 
differences in HIV pathogenesis between young and aged patients, we surveyed 83 HIV patients, 33 of which were $>50$ years old. Among the young and aged groups, $40 \%$ of each group was classified as normal brain pathology; however, $18 \%$ of the aged group presented with Alzheimer type II gliosis in contrast to only one patient from the young group. Also noteworthy, $34 \%$ of the young group had encephalitis versus $24 \%$ of the aged group. High VL and encephalitis may have contributed to the premature demise of young patients, whereas persistent low-level infection, as seen in aged patients, may contribute to the Alzheimer-like pathology. In contrast to past reports, the current studies indicate that CD4+ cell count was higher in aged brains, and CNS plasma viral burden is reduced in aged HIV patients; yet, p24 and inflammatory markers are increased compared to their younger counterparts. Chronic inflammation may promote long-term deleterious changes in gene expression in aged HIV infected individuals, which may explain how aged HIV patients suffer increased morbidity despite higher CD4+ cell counts. Cohort size and population dynamics all contribute to data variability.

The proportion of HIV-1-infected individuals over the age of 50 is rapidly increasing, yet therapies to prevent or treat HAND remain scant (Erlandson et al. 2012; Watkins and Treisman 2012). Furthermore, the HIV-infected population is not alone as the average age of the general population is increasing along with the prevalence of ageassociated neurodegenerative diseases. These studies implicate autophagy as a novel target for preventing and treating HAND, AD, PD, and possibly other neurodegenerative disorders. Importantly, this report suggests that young and aged HIV patients may require unique drug regimens to combat progression in these two distinct stages of disease.

Acknowledgments We thank the National Institutes of Aging (AG043384) and the National Institutes of Mental Health for (MH062962, MH5974 and MH83506) funding this work.

Open Access This article is distributed under the terms of the Creative Commons Attribution License which permits any use, distribution, and reproduction in any medium, provided the original author(s) and the source are credited.

\section{References}

Achim CL, Adame A, Dumaop W, Everall IP, Masliah E (2009) Increased accumulation of intraneuronal amyloid beta in HIVinfected patients. J Neuroimmune Pharmacol 4:190-199

Alirezaei M, Kiosses WB, Flynn CT, Brady NR, Fox HS (2008a) Disruption of neuronal autophagy by infected microglia results in neurodegeneration. PLoS One 3:e2906

Alirezaei M, Kiosses WB, Fox HS (2008b) Decreased neuronal autophagy in HIV dementia: a mechanism of indirect neurotoxicity. Autophagy 4:963-966
Budka H, Costanzi G, Cristina S, Lechi A, Parravicini C, Trabattoni R, Vago L (1987) Brain pathology induced by infection with the human immunodeficiency virus (HIV). A histological, immunocytochemical, and electron microscopical study of 100 autopsy cases. Acta Neuropathol(Berl) 75:185-198

Carroll-Anzinger D, Al-Harthi L (2006) Gamma interferon primes productive human immunodeficiency virus infection in astrocytes. J Virol 80:541-544

Cherner M, Cysique L, Heaton RK, Marcotte TD, Ellis RJ, Masliah E, Grant I (2007) Neuropathologic confirmation of definitional criteria for human immunodeficiency virus-associated neurocognitive disorders. J Neurovirol 13:23-28

Codogno P, Mehrpour M, Proikas-Cezanne T (2012) Canonical and non-canonical autophagy: variations on a common theme of selfeating? Nat Rev Mol Cell Biol 13:7-12

Crews L, Spencer B, Desplats P, Patrick C, Paulino A, Rockenstein E, Hansen L, Adame A, Galasko D, Masliah E (2010) Selective molecular alterations in the autophagy pathway in patients with Lewy body disease and in models of alpha-synucleinopathy. PLoS One 5:e9313

Cuervo AM (2004) Autophagy: in sickness and in health. Trends Cell Biol 14:70-77

Cuervo AM, Stefanis L, Fredenburg R, Lansbury PT, Sulzer D (2004) Impaired degradation of mutant alpha-synuclein by chaperonemediated autophagy. Science 305:1292-1295

Dinkins C, Arko-Mensah J, Deretic V (2010) Autophagy and HIV. Semin Cell Dev Biol 21:712-718

Ebrahimi-Fakhari D, Cantuti-Castelvetri I, Fan Z, Rockenstein E, Masliah E, Hyman BT, McLean PJ, Unni VK (2011) Distinct roles in vivo for the ubiquitin-proteasome system and the autophagy-lysosomal pathway in the degradation of alpha-synuclein. The $J$ of neurosci: the official $j$ of the Soc for Neurosci 31:14508-14520

Erlandson KM, Allshouse AA, Duong S, Mawhinney S, Kohrt WM, Campbell TB (2012) HIV, aging, and advance care planning: are we successfully planning for the future? J Palliat Med 15(10):1124 1129

Everall I, Vaida F, Khanlou N, Lazzaretto D, Achim C, Letendre S, Moore D, Ellis R, Cherne M, Gelman B, Morgello S, Singer E, Grant I, Masliah E (2009) Cliniconeuropathologic correlates of human immunodeficiency virus in the era of antiretroviral therapy. J Neurovirol 15(5-6):360-370

Franklin KBJ, Paxinos G (1997) The mouse brain in stereotaxic coordinates. Academic Press, San Diego

Gannage M, Ramer PC, Munz C (2010) Targeting Beclin 1 for viral subversion of macroautophagy. Autophagy 6:166-167

Gendelman HE, Persidsky Y, Ghorpade A, Limoges J, Stins M, Fiala M, Morrisett R (1997) The neuropathogenesis of the AIDS dementia complex. Aids 11(A):S35-S45

Gonzalez-Scarano F, Martin-Garcia J (2005) The neuropathogenesis of AIDS. Nat Rev Immunol 5:69-81

Gozuacik D, Kimchi A (2004) Autophagy as a cell death and tumor suppressor mechanism. Oncogene 23:2891-2906

Gregoire IP, Richetta C, Meyniel-Schicklin L, Borel S, Pradezynski F, Diaz O, Deloire A, Azocar O, Baguet J, Le Breton M, Mangeot PE, Navratil V, Joubert PE, Flacher M, Vidalain PO, Andre P, Lotteau V, Biard-Piechaczyk M, Rabourdin-Combe C, Faure M (2011) IRGM is a common target of RNA viruses that subvert the autophagy network. PLoS Pathog 7:e1002422

Haas DW, Clough LA, Johnson BW, Harris VL, Spearman P, Wilkinson GR, Fletcher CV, Fiscus S, Raffanti S, Donlon R, McKinsey J, Nicotera J, Schmidt D, Shoup RE, Kates RE, Lloyd RM Jr, Larder B (2000) Evidence of a source of HIV type 1 within the central nervous system by ultraintensive sampling of cerebrospinal fluid and plasma. AIDS Res Hum Retrovir 16:1491-1502

Hashimoto M, Sagara Y, Everall IP, Mallory M, Everson A, Langford D, Masliah E (2002) Fibroblast growth factor 1 regulates 
signaling via the GSK3 \{beta\} pathway: implications for neuroprotection. J Biol Chem 277:32985-32991

Heaton RK, Clifford DB, Franklin DR Jr, Woods SP, Ake C, Vaida F, Ellis RJ, Letendre SL, Marcotte TD, Atkinson JH, Rivera-Mindt M, Vigil OR, Taylor MJ, Collier AC, Marra CM, Gelman BB, McArthur JC, Morgello S, Simpson DM, McCutchan JA, Abramson I, Gamst A, Fennema-Notestine C, Jernigan TL, Wong J, Grant I (2010) HIV-associated neurocognitive disorders persist in the era of potent antiretroviral therapy: CHARTER Study. Neurology 75:2087-2096

Heaton RK, Franklin DR, Ellis RJ, McCutchan JA, Letendre SL, Leblanc S, Corkran SH, Duarte NA, Clifford DB, Woods SP, Collier AC, Marra CM, Morgello S, Mindt MR, Taylor MJ, Marcotte TD, Atkinson JH, Wolfson T, Gelman BB, McArthur JC, Simpson DM, Abramson I, Gamst A, Fennema-Notestine C, Jernigan TL, Wong J, Grant I (2011) HIV-associated neurocognitive disorders before and during the era of combination antiretroviral therapy: differences in rates, nature, and predictors. $\mathrm{J}$ Neurovirol 17:3-16

Jaeger PA, Wyss-Coray T (2010) Beclin 1 complex in autophagy and Alzheimer disease. Arch Neurol 67:1181-1184

Joska JA, Gouse H, Paul RH, Stein DJ, Flisher AJ (2010) Does highly active antiretroviral therapy improve neurocognitive function? A systematic review. J Neurovirol 16:101-114

Kaul M, Garden GA, Lipton SA (2001) Pathways to neuronal injury and apoptosis in HIV-associated dementia. Nature 410:988-994

Khanlou N, Moore DJ, Chana G, Cherner M, Lazzaretto D, Dawes S, Grant I, Masliah E, Everall IP (2009) Increased frequency of alpha-synuclein in the substantia nigra in human immunodeficiency virus infection. J Neurovirol 15:131-138

Killian MS (2012) Dual role of autophagy in HIV-1 replication and pathogenesis. AIDS Res Ther 9:16

Kragh CL, Ubhi K, Wyss-Corey T, Masliah E (2012) Autophagy in dementias. Brain pathol 22:99-109

Kyei GB, Dinkins C, Davis AS, Roberts E, Singh SB, Dong C, Wu L, Kominami E, Ueno T, Yamamoto A, Federico M, Panganiban A, Vergne I, Deretic V (2009) Autophagy pathway intersects with HIV-1 biosynthesis and regulates viral yields in macrophages. $\mathrm{J}$ Cell Biol 186:255-268

Lipton SA (1994) AIDS-related dementia and calcium homeostasis. Ann N Y Acad Sci 747:205-224

Marr RA, Rockenstein E, Mukherjee A, Kindy MS, Hersh LB, Gage FH, Verma IM, Masliah E (2003) Neprilysin gene transfer reduces human amyloid pathology in transgenic mice. J Neurosci 23:1992-1996

Masliah E, Alford M, Adame A, Rockenstein E, Galasko D, Salmon D, Hansen LA, Thal LJ (2003) Abeta1-42 promotes cholinergic sprouting in patients with $\mathrm{AD}$ and Lewy body variant of $\mathrm{AD}$. Neurology 61:206-211

Naldini L, Blomer U, Gage FH, Trono D, Verma IM (1996a) Efficient transfer, integration, and sustained long-term expression of the transgene in adult rat brains injected with a lentiviral vector. Proc Natl Acad Sci U S A 93:11382-11388

Naldini L, Blomer U, Gallay P, Ory D, Mulligan R, Gage FH, Verma IM, Trono D (1996b) In vivo gene delivery and stable transduction of nondividing cells by a lentiviral vector. Science 272:263-267

Nath A (2002) Human immunodeficiency virus (HIV) proteins in neuropathogenesis of HIV dementia. J Infect Dis 186(Suppl 2): S193-S198

Nath A, Haughey NJ, Jones M, Anderson C, Bell JE, Geiger JD (2000) Synergistic neurotoxicity by human immunodeficiency virus proteins Tat and gp120: protection by memantine. Ann Neurol 47:186-194

Nixon RA, Wegiel J, Kumar A, Yu WH, Peterhoff C, Cataldo A, Cuervo AM (2005) Extensive involvement of autophagy in Alzheimer disease: an immuno-electron microscopy study. J Neuropathol Exp Neurol 64:113-122

Norman JP, Perry SW, Reynolds HM, Kiebala M, De Mesy Bentley KL, Trejo M, Volsky DJ, Maggirwar SB, Dewhurst S, Masliah E, Gelbard HA (2008) HIV-1 Tat activates neuronal ryanodine receptors with rapid induction of the unfolded protein response and mitochondrial hyperpolarization. PLoS One 3:e3731

Patrick C, Crews L, Desplats P, Dumaop W, Rockenstein E, Achim CL, Everall IP, Masliah E (2011) Increased CDK5 expression in HIV encephalitis contributes to neurodegeneration via Tau phosphorylation and is reversed with roscovitine. Am J Pathol 178:1646-1661

Pickford F, Masliah E, Britschgi M, Lucin K, Narasimhan R, Jaeger PA, Small S, Spencer B, Rockenstein E, Levine B, Wyss-Coray T (2008) The autophagy-related protein beclin 1 shows reduced expression in early Alzheimer disease and regulates amyloid beta accumulation in mice. J Clin Invest 118:2190-2199

Rockenstein E, Mante M, Alford M, Adame A, Crews L, Hashimoto M, Esposito L, Mucke L, Masliah E (2005a) High beta-secretase activity elicits neurodegeneration in transgenic mice despite reductions in amyloid-beta levels: implications for the treatment of Alzheimer disease. J Biol Chem 280:32957-32967

Rockenstein E, Schwach G, Ingolic E, Adame A, Crews L, Mante M, Pfragner R, Schreiner E, Windisch M, Masliah E (2005b) Lysosomal pathology associated with alpha-synuclein accumulation in transgenic models using an eGFP fusion protein. J Neurosci Res $80: 247-259$

Scott JC, Woods SP, Carey CL, Weber E, Bondi MW, Grant I (2011) Neurocognitive consequences of HIV infection in older adults: an evaluation of the "cortical" hypothesis. AIDS Behav 15:1187-1196

Smith G (2005). Statement of Senator Gordon H. Smith. Aging hearing: HIV over fifty, exploring the new threat. In: Senate Committee on Aging: Washington, DC

Spencer B, Potkar R, Trejo M, Rockenstein E, Patrick C, Gindi R, Adame A, Wyss-Coray T, Masliah E (2009) Beclin 1 gene transfer activates autophagy and ameliorates the neurodegenerative pathology in alpha-synuclein models of Parkinson's and Lewy body diseases. J Neurosci 29:13578-13588

Tiscornia G, Singer O, Verma IM (2006) Design and cloning of lentiviral vectors expressing small interfering RNAs. Nat Protoc $1: 234-240$

Toggas SM, Masliah E, Rockenstein EM, Rall GF, Abraham CR, Mucke L (1994) Central nervous system damage produced by expression of the HIV-1 coat protein gp120 in transgenic mice. Nature 367:188-193

Van Grol J, Subauste C, Andrade RM, Fujinaga K, Nelson J, Subauste CS (2010) HIV-1 inhibits autophagy in bystander macrophage/ monocytic cells through Src-Akt and STAT3. PLoS One 5:e11733

Watkins CC, Treisman GJ (2012) Neuropsychiatric complications of aging with HIV. J Neurovirol 18:277-290

Wiley C, Achim C (1994) HIV encephalitis is the pathologic correlate of dementia in AIDS. AnnNeurol 36:673-676

Wiley CA, Baldwin M, Achim CL (1996) Expression of HIV regulatory and structural mRNA in the central nervous system. AIDS 10:843-847

Zhou D, Masliah E, Spector SA (2011) Autophagy is increased in postmortem brains of persons with HIV-1-associated encephalitis. J Infect Dis 203:1647-1657 